\title{
Ion upflow and downflow at the topside ionosphere observed by the EISCAT VHF radar
}

\author{
M. Endo ${ }^{1}$, R. Fujii ${ }^{1}$, Y. Ogawa ${ }^{1}$, S. C. Buchert ${ }^{1}$, S. Nozawa ${ }^{1}$, S. Watanabe ${ }^{2}$, N. Yoshida ${ }^{3}$ \\ ${ }^{1}$ Solar-Terrestrial Environment Laboratory, Nagoya University, Furo-cho, Chikusa-ku, Nagoya 464-8601, Japan \\ E-mail: rfujii@stelab.nagoya-u.ac.jp \\ ${ }^{2}$ Department of Earth and Planetary Sciences, Hokkaido University, Sapporo 060-0810, Japan \\ ${ }^{3}$ The Graduate School of Science, Tohoku University, Sendai 980-8578, Japan
}

Received: 27 January 1999 / Revised: 6 October 1999 / Accepted: 7 October 1999

\begin{abstract}
We have determined the MLT distribution and $K_{P}$ dependence of the ion upflow and downflow of the thermal bulk oxygen ion population based on a data analysis using the EISCAT VHF radar CP-7 data obtained at Tromsø during the period between 1990 and 1996: (1) both ion upflow and downflow events can be observed at any local time (MLT), irrespective of dayside and nightside, and under any magnetic disturbance level, irrespective of quiet and disturbed levels; (2) these upflow and downflow events are more frequently observed in the nightside than in the dayside; (3) the upflow events are more frequently observed than the downflow events at any local time except midnight and at any $K_{P}$ level and the difference of the occurrence frequencies between the upflow and downflow events is smaller around midnight; and (4) the occurrence frequencies of both the ion upflow and downflow events appear to increase with increasing $K_{P}$ level, while the occurrence frequency of the downflow appears to stop increasing at some $K_{P}$ level.
\end{abstract}

Key words: Ionosphere (particle acceleration; plasma waves and instabilities) - Space plasma physics (transport processes)

\section{Introduction}

The polar wind is a field-aligned ion flow from the polar ionosphere to the magnetosphere (Axford, 1968). Dessler and Michel (1996), Bauer (1966), and Nishida (1966) suggested that a "continuous" escape of thermal light ions such as $\mathrm{H}^{+}$and $\mathrm{He}^{+}$should occur due to

Correspondence to: R. Fujii ambipolar diffusion along the geomagnetic open field line.

A number of models of the polar wind have been proposed; hydrodynamic models (Banks and Holzer, 1968, 1969a, b; Marubashi, 1970; Raitt et al., 1975, 1977; Schunk et al., 1978), kinetic models (Lemaire and Scherer, 1970, 1973), models solving the generalized transport equations (Schunk and Watkins, 1981, 1982; Demars and Schunk, 1987; Ganguli et al., 1987) and time-dependent models (Gombosi and Nagy, 1989; Schunk and Sojka, 1989). Polar wind observations are dated from the early years of the 1970s with the Explorer 31, OGO 2, and ISIS 2 satellites (Hoffman, 1970; Taylor and Walsh, 1972; Hoffman et al., 1974) and in the 1980s case studies of the polar wind were carried out based on data obtained from the Dynamic Explorer (DE) 1 satellite (Shelley et al., 1982; Nagai et al., 1984; Chandler et al., 1991).

Recent observations with satellites such as Akebono (EXOS-D) and GEOTAIL have shown that thermal ions, including not only light ions $\mathrm{H}^{+}$and $\mathrm{He}^{+}$but also heavy ions $\mathrm{O}^{+}$and $\mathrm{NO}^{+}$flow out of the polar ionosphere and they are found in the lower magnetosphere (Watanabe et al., 1992; Abe et al., 1993a, b; Yau et al., 1991, 1993, 1995) and in the lobe magnetosphere (Mukai et al., 1994; Hirahara et al., 1996; Seki et al., 1996, 1998). A very comprehensive review of the terrestrial plasma source obtained from the DE mission was given by Chappell (1988).

The "classical" polar wind theory can only be applicable, however, to the upward flow of thermal light ions such as $\mathrm{H}^{+}$and $\mathrm{He}^{+}$in the polar cap region. The heavy ions escaping from the ionosphere to the magnetosphere require additional energy source. In other words, some other physical processes rather than ambipolar diffusion must be involved in accelerating heavy ions from the polar ionosphere since the heavy ions driven only by ambipolar diffusion are not able to overcome the Earth's gravity and furthermore they are likely to be lost by a charge exchange reaction $\mathrm{O}^{+}+\mathrm{H} \leftrightarrows \mathrm{H}^{+}+\mathrm{O}$ in the topside ionosphere and 
$\mathrm{O}+\mathrm{O}^{+} \rightarrow \mathrm{O}^{+}+\mathrm{O}$ in the $\mathrm{F}$ region (Moore, 1984). Simulations have concentrated on the effects of ion frictional heating in the presence of large electric fields (Loranc and St.-Maurice, 1994; Wilson, 1994). Outflow could be reproduced during conditions of very strong heating. Satellite observations and theory of ion outflow were recently reviewed by Yau and André (1997), André and Yau (1997), and Horwitz and Moore (1997).

Although extensive satellite observations at altitudes of more than $1000 \mathrm{~km}$ have been made, what seems to be lacking is observations below $1000 \mathrm{~km}$ where the light and heavy ions are likely to be heated and/or accelerated and start to flow. Generally, it is difficult to observe altitude profiles of several parameters in the $\mathrm{F}$ region by means of satellites. On the other hand, radar observations in the polar region, such as EISCAT radar, are ideal for ion upflow studies in the $\mathrm{F}$ region.

A number of authors studied ion upflow events based on data obtained from the EISCAT radar in Scandinavia (Blelly et al., 1992a, b; Wu et al., 1992; Wahlund et al., 1992). They found that ion upflow can occur above Tromsø located at 66 invariant latitude, which is presumed to be on and inside the polar cap boundary only occasionally. This may suggest that the ion upflow can occur in the closed field line region. Wahlund et al. (1992) also disclosed that the ion upflow event is often associated with the enhancement of the electron and/ or ion temperatures. The previous studies concentrated on case studies, while there have been few studies on statistical characteristics of the ion upflow with EISCAT.

The present study aims at determining the statistical characteristics of ion upflow and downflow based on an analysis using Common Program 7 (CP 7) data obtained from the EISCAT VHF radar. As we show in later sections, the ion upflow and downflow events we have considered do not have continuous features but have intermittent features with only a few minutes to a few tens of minutes from appearance to disappearance, which may consist of bursts with shorter time duration (Wahlund et al., 1993). We therefore think that the upflow ions we consider are upgoing ions heated up and accelerated in the topside ionosphere rather than classical polar wind ions. We will focus particularly on the magnetic local time (MLT) distribution of the occurrence frequency of these ion upflow and downflow events, and their dependence on magnetic disturbances, for which we will use the $K_{P}$ index.

\section{Observations}

The EISCAT VHF radar (224 MHz), located at Ramfjord near Tromsø $(69.6 \mathrm{~N}, 19.2 \mathrm{E})$, Norway, is a monostatic system using a $120 \times 40 \mathrm{~m}$ parabolic cylinder antenna, divided into four sectors. These sectors can be individually steered in the meridian plane from $30^{\circ}$ south to $60^{\circ}$ north of the zenith (EISCAT Scientific Association, 1991). The Common Programme 7 (CP 7) is one of the seven EISCAT CPs and one of the three CPs using VHF radars. A $900 \mu$ s pulse is used to sample
21 signal gates at about $65 \mathrm{~km}$ increments in range, with the first gate at $285 \mathrm{~km}$ range and the last gate at $1654 \mathrm{~km}$ range. Vertical antenna pointing is used.

We have used 22 sets of the EISCAT CP7 data that cover all CP 7 data during the period between 1990 and 1996, for about $820 \mathrm{~h}$ altogether. The data used in this study are listed in Table 1. The data integration is $5 \mathrm{~min}$, but for some datasets (marked ${ }^{\mathrm{a}}$ ) it is $2.5 \mathrm{~min}$ and for some others (marked ${ }^{\mathrm{b}}$ ) it is $2 \mathrm{~min}$.

The standard EISCAT program was used for the analysis of the raw data. This assumes $100 \% \mathrm{O}^{+}$ throughout the upper $\mathrm{F}$ region, no $\mathrm{H}^{+}$or $\mathrm{He}^{+}$. So far substantial fractions of light ions have rarely been observed with the VHF radar even at altitudes up to about $1600 \mathrm{~km}$. Furthermore, in this study only the fitted velocities are used, which should not suffer from significant errors, even if the assumed ion composition is biased. It has been reported that associated with ion upflow frequently naturally enhanced ion-acoustic lines occur (Rietveld et al., 1991; Wahlund et al., 1992, 1993). These are not normal IS spectra, but show asymmetrical features. In the present study we have excluded only the strongest of these abnormal spectra that lead to a digital overflow in the EISCAT correlator. The typical duration of an event with naturally enhanced ion-acoustic lines is about 1 min (Rietveld et al., 1991). Since our integration time is mostly $5 \mathrm{~min}$, the effect of the weaker abnormal spectra on the fitted velocity should be relatively small. Recently Forme and Fontaine (1999) studied the Doppler velocity during naturally enhanced ion lines with a new technique. They found that in all the events studied the ion flow speed was upward before the enhancement, and the spectra became even more Doppler shifted during the event. The velocities used in this study might therefore be occasionally somewhat

Table 1. Data used in this study

\begin{tabular}{lllll}
\hline Number & Start date & Time $(\mathrm{UT})$ & End date & Time $(\mathrm{UT})$ \\
\hline 1 & 900925 & 1000 & 900927 & 1200 \\
2 & 910512 & 1000 & 910515 & 0700 \\
3 & 911028 & 1000 & 911029 & 1600 \\
4 & 920211 & 1000 & 920212 & 1600 \\
5 & 920505 & 1000 & 920506 & 1600 \\
6 & 921215 & 1500 & 921217 & 1900 \\
$7^{\mathrm{a}}$ & 930216 & 1100 & 930217 & 2200 \\
$8^{\mathrm{a}}$ & 930317 & 1900 & 930318 & 2200 \\
$9^{\mathrm{a}}$ & 930518 & 1200 & 930519 & 2200 \\
$10^{\mathrm{a}}$ & 931109 & 1200 & 931110 & 2300 \\
$11^{\mathrm{a}}$ & 940207 & 2200 & 940209 & 2300 \\
12 & 940412 & 1600 & 940413 & 2200 \\
13 & 940503 & 1200 & 940504 & 2200 \\
14 & 940906 & 1900 & 940907 & 2200 \\
$15^{\mathrm{a}}$ & 941004 & 1400 & 941005 & 2400 \\
16 & 950201 & 0900 & 950204 & 0900 \\
17 & 950328 & 1500 & 950329 & 2000 \\
$18^{\mathrm{b}}$ & 950927 & 0900 & 950928 & 1600 \\
$19^{\mathrm{b}}$ & 961015 & 1000 & 961015 & 1400 \\
20 & 961111 & 1000 & 961115 & 1600 \\
21 & 961116 & 0500 & 961116 & 0900 \\
22 & 961121 & 1600 & 961121 & 2400 \\
\hline
\end{tabular}

a 2.5 min data integration; ${ }^{\mathrm{b}} 2$ min data integration 
overestimated, because weak abnormal spectra were not excluded. As will be discussed in the next section, the velocity will mainly be used to define upflow events or occurrence. In a future study, we will also address fluxes and temperatures. Then the data will have to be carefully screened from abnormal spectra.

There can be at least three major errors/uncertainties in CP-7 data. First, the data suffer from the thermal noise of the receiving system. Furthermore, the uncertainty of the parameters increases with the increasing altitudes due to the corresponding decrease of the strength of the receiving signals. Second, the data processing to determine several qualities such as the line-of-sight velocity should include some errors due to insufficient fitting of an observed spectrum with a theoretical IS spectrum. Third, temporal variations of the parameters within the integrated time period also provide an uncertainty of the data.

Figure 1a shows a typical example of the ion upflow event observed between 1745 and 1830 UT on May 13, 1991, where we show 9 time sequential height profiles of the vertical ion velocity. The abscissa shows the vertical ion velocity where a positive (negative) value means ions moving upward (downward). The ordinate is the height from $200 \mathrm{~km}$ to $1700 \mathrm{~km}$. Each circle denotes the ion velocity at a corresponding altitude with a horizontal bar showing one-sigma error. The quality of the data vary (see figure caption).

Between 1745 and 1800 UT there are no significant enhancements of the ion velocity at any height. At 1800 1805 UT the ion velocity becomes positive, implying that ions start to move upward, above say $900 \mathrm{~km}$ with the largest velocity of about $500 \mathrm{~m} / \mathrm{s}$ around $1300 \mathrm{~km}$. During the next five minutes between 1805 and 1810 UT, lower altitude ions also start to move, with the lowest altitude of the ion upflow of $600 \mathrm{~km}$ and the largest velocity of $800 \mathrm{~m} / \mathrm{s}$ around $1200 \mathrm{~km}$. Five minutes later, the maximum velocity becomes larger, $1300 \mathrm{~m} / \mathrm{s}$ with the altitude of the maximum velocity becoming higher, up to around $1500 \mathrm{~km}$. The ion upflow then fades away and returns to the previous (quiet) level at 1745-1750 UT. Generally, as shown here, the ion upflow appears to be a transient phenomena on a time scale of minutes.

Figure $1 \mathrm{~b}$ shows an example of the ion downflow event observed between 1940 and 2025 UT on September 26, 1990, where we show again 9 sequential height profiles of the ion velocity. The format is same as for Fig. 1a. Ion downflow is seen between 1945 and 2010 UT, although the data quality is not good above $1300 \mathrm{~km}$. The ion downflow appears to be also a transient phenomenon, as for the ion upflow in Fig. 1a.

Figure 2 shows a height profile of the ion velocity, where we have over-plotted all the data points for $69 \mathrm{~h}$ from 1000 UT of May 12 to 0645 UT of May 15, 1990. The ion velocity for the majority of the data is concentrated in a certain velocity range around zero; this range changes depending on the altitude, that is, $\pm 100 \mathrm{~m} / \mathrm{s}$ at $300 \mathrm{~km}, \pm 200 \mathrm{~m} / \mathrm{s}$ at $800 \mathrm{~km}$, and $\pm 400 \mathrm{~m} / \mathrm{s}$ at $1400 \mathrm{~km}$. The ion velocity for other data deviates from this concentration. Positive deviations corresponding to the ion upflow are more pronounced than negative ones corresponding to the downflow. This profile again shows that the ion upflow starts to appear at some altitude, often above $600 \mathrm{~km}$. The average velocities denoted by a thin line are positive, implicitly suggesting that the velocity of the ion upflow is stronger than that of the downflow.

\section{Statistical analysis}

We have used the following quantitative definition for selecting the ion upflow and downflow events from the CP 7 database. We have set two conditions which the ion upflow and downflow must satisfy. The first condition is that the altitudinal gradient $\nabla_{1}$ of the ion velocity is more than a certain value A1 for $N$ consecutive heights. $N$ is 3 for an example obtained at 0740-0745 UT on May 14, 1991, shown in Fig. 3. The second condition is that the maximum velocity $\mathrm{V}_{\max }$ is more than A2. Furthermore, the lowest altitude of the ion upflow and downflow is defined to be an altitude where, for the first time, the absolute value of the altitudinal gradient $\nabla_{3}$ of the ion velocity exceeds a certain value $\mathrm{A} 3$. We have set three threshold criteria for these conditions from less severe to severe, as tabulated in Table 2, in order to check whether the choice of the threshold criteria of the conditions affects the statistical characteristics of the ion upflow and downflow.

Figure 4 shows the magnetic local time (MLT) distributions of the occurrence frequency of the ion upflow (on the left-hand side) and the downflow (on the right-hand side) for case 1 through case 3 . For both ion upflow and downflow, only data under $K_{P}<4$ are selected. We have used, throughout the present work, the occurrence frequency of the ion upflow and downflow, which is defined as $B / A$, where $B$ is the number of the ion upflow (or downflow) and $A$ is the total number of samples during a certain period. For Fig. 4 the abscissa is MLT (from 0000 to 2400 MLT) with each bin of $5 \mathrm{~min}$. The horizontal line is the occurrence frequency averaged over the 24 MLT hours.

With increasing the threshold criterion, the occurrence frequency decreases, because the occurrence of the ion upflow (or downflow) decreases while the total number of samples does not change. (This is also evident from the average occurrence frequencies.) It should be noted, however, that the MLT dependence, that is, relative increase/decrease of the occurrence frequency for both ion upflow and downflow by MLT, is retained regardless of the threshold criterion. For the ion upflow, for example, several maxima around 05, $10,17,20-01$ MLT and minima around 08 and 19 MLT are commonly recognised for all threshold criteria. For the downflow, maxima around 01, 06, 11, 23 MLT and some minima are also commonly seen for all threshold criteria. Since the choice of the threshold criteria does not change the characteristics of the MLT dependence and $K_{P}$ dependence (not shown here), hereinafter we will show results only for the threshold criterion 2 . 

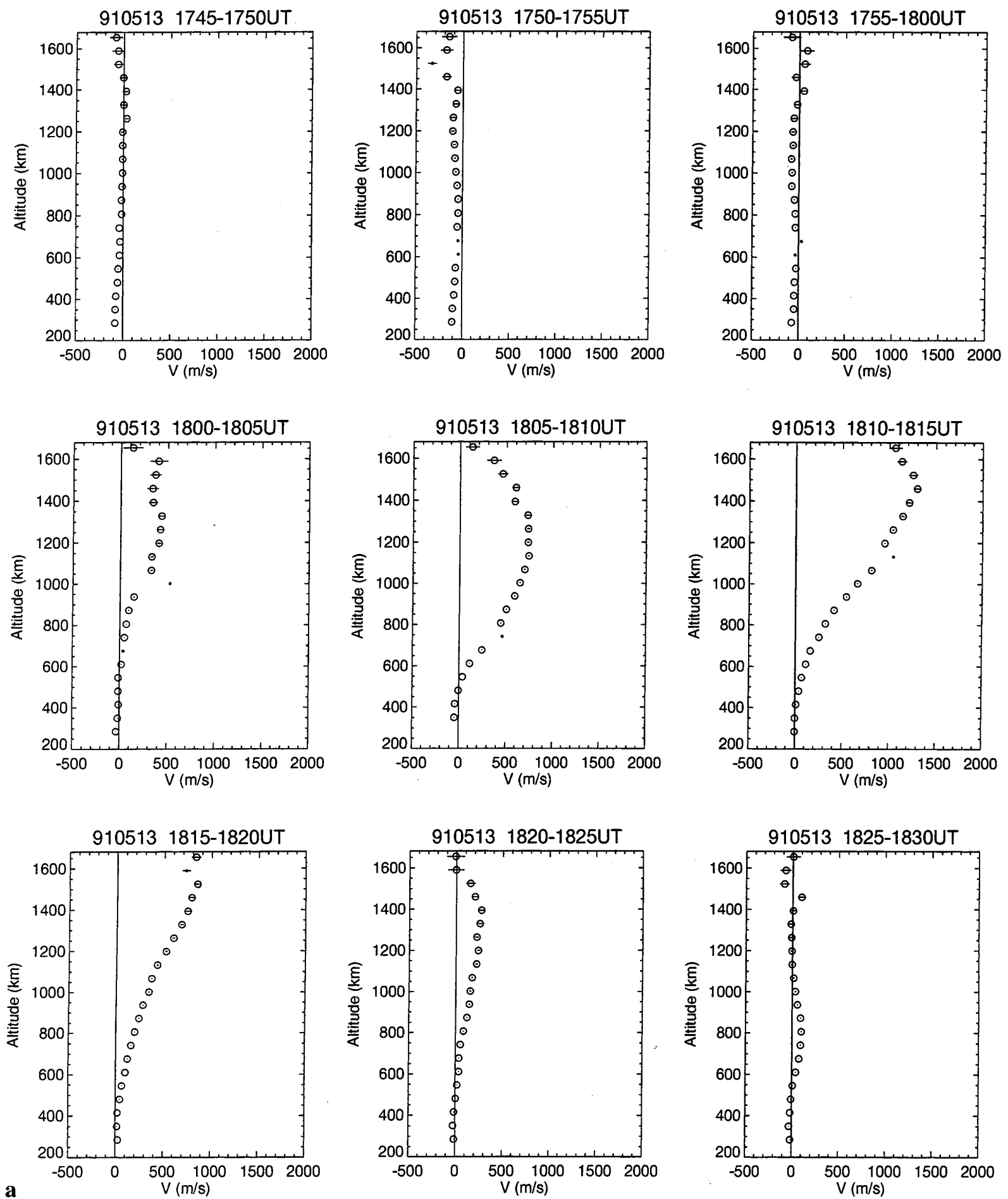

Fig. 1. a Typical examples of the ion upflow observed at $1745-1830$ UT on May 13, 1991 and $\mathbf{b}$ ion downflow observed between 1940 and 2025 UT on September 26, 1990. Each figure contains 9 time sequential height profiles of the vertical ion velocity. The abscissa shows the vertical ion velocity where a positive (negative) value means

ions moving upward (downward). The circles represent good quality data and the dots represent not very good quality data judging from the degree to which well-observed EISCAT spectrum is fitted to a theoretical spectrum

Figure 5 shows the distributions of the upflow and downflow for four magnetic local time regions: $21 \leq$ MLT $<3,3 \leq$ MLT $<9,9 \leq$ MLT $<15$, and $15 \leq$ MLT $<21$, under two geomagnetic disturbance levels: $K_{P}<4$ for quiet conditions and $K_{P} \geq 4$ for disturbed conditions. More quantitative $K_{P}$ dependence will be shown later. The occurrence frequencies of the upflow and downflow are denoted by thick and thin vertical bars and those averaged over 24 MLT hours are shown by solid and dotted horizontal lines, respectively.

The top panels show the occurrence frequency. For both $K_{P}$ levels, the occurrence frequencies of ion upflow 

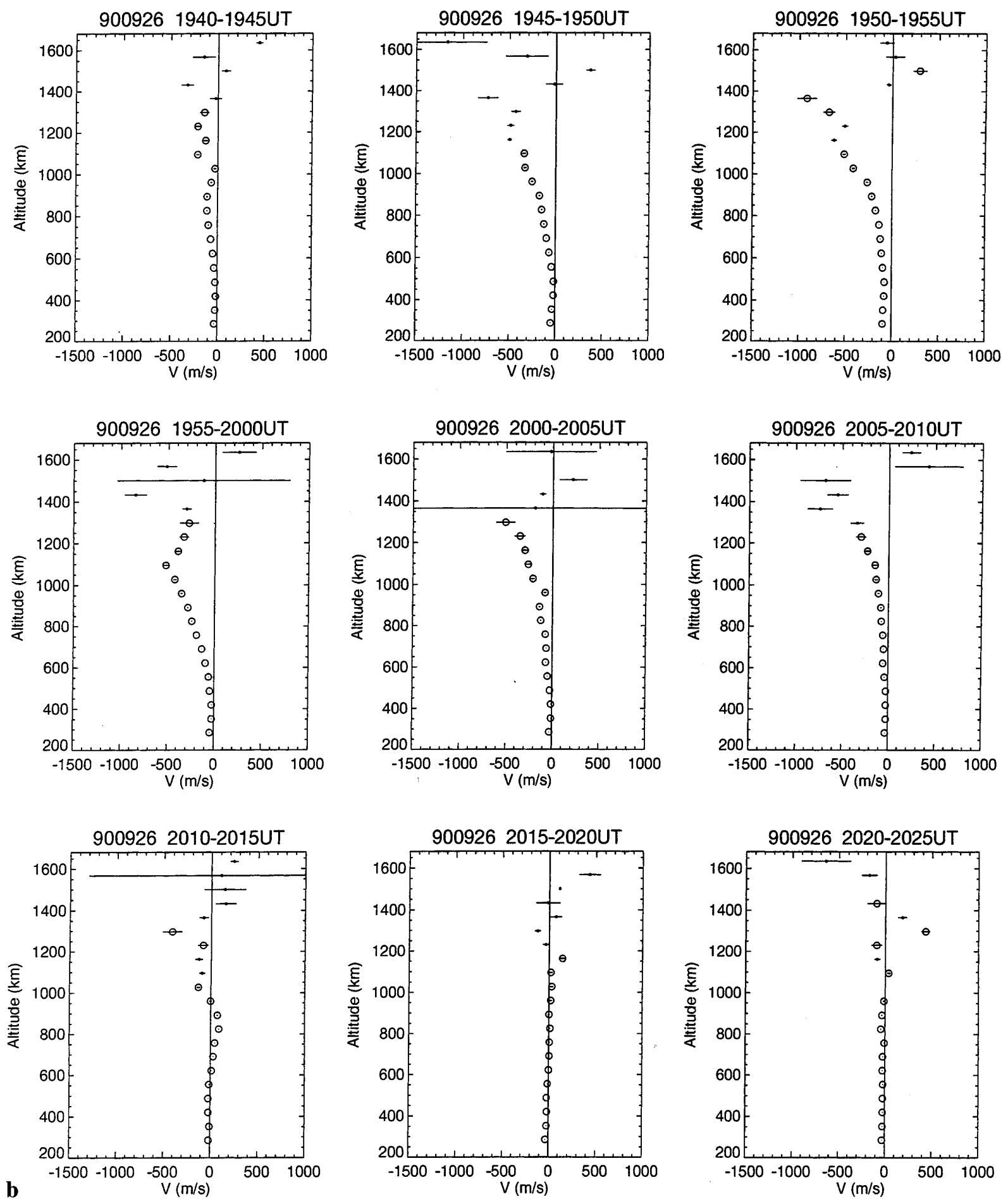

Fig. 1. (Contd.)

and downflow are smaller in the midday and becomes larger in the nightside region. The occurrence frequency of the upflow is generally larger than that of the downflow except for midnight and midday periods under the lower $K_{P}$ level where these two occurrence frequencies are nearly the same or the occurrence frequency of the downflow slightly dominates over that of the upflow. When the $K_{P}$ level becomes higher, the occurrence frequency of the upflow generally becomes greater, while that of the downflow does not change so much for $21 \leq$ MLT $<3$ and $9 \leq$ MLT $<15$. This tendency is also clearly seen in the large increase of the average occurrence frequency of the upflow but a smaller increase of the downflow, with increasing $K_{P}$ level.

The middle and bottom panels show the duration and the maximum velocity of the upflow and downflow. The ion upflow and downflow have a duration of the order of and possibly shorter than the integration period used. The MLT distribution of the maximum velocities 


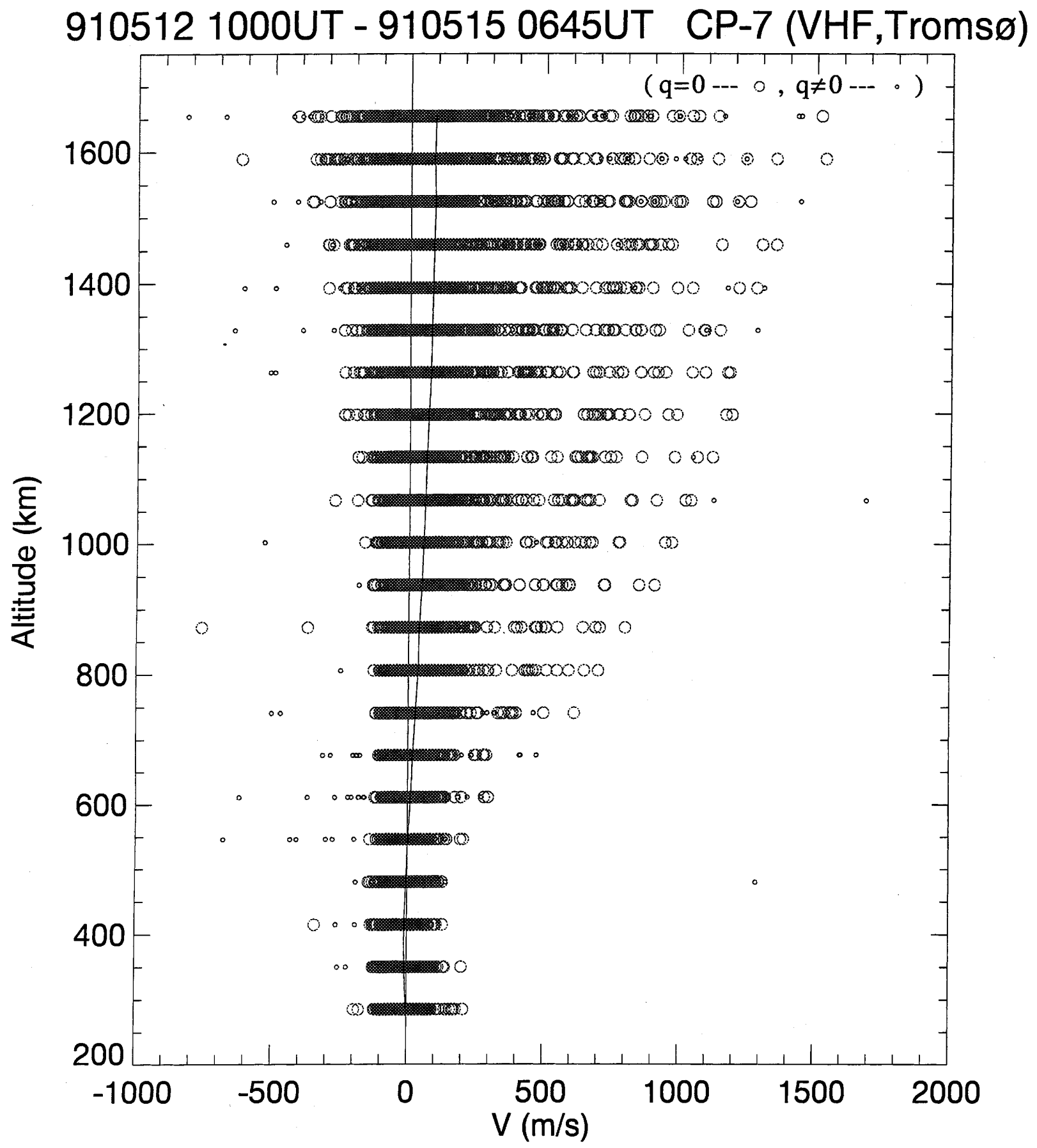

Fig. 2. An over-plotted height profile of the ion velocity for $69 \mathrm{~h}$ from 1000 UT on May 12 to 0645 UT on May 15, 1990. The ion velocity for the majority of the data is concentrated in a certain

velocity range around zero. The ion velocity for other data shows that the ion upflow starts to appear at altitude, often above $600 \mathrm{~km}$

shows small differences between the two $K_{P}$ levels and furthermore the difference of the occurrence frequency between the upflow and downflow becomes larger with the higher $K_{P}$ level except the midday region.

The $K_{P}$ dependence of the ion upflow and downflow for all MLTs is shown in Fig. 6. The abscissa is the $K_{P}$ level from 0 to 8 . The ordinate is the occurrence frequency for the lines with circles and the number of samples for each $K_{P}$ bin. A $K_{P}$ bin ' $N$ ' includes actually three $K_{P}$ levels; $N^{-}, N$, and $N^{+}$. The numbers of sampling for bins from 0 to 6 are respectively more than
500 with relative uncertainties of less than $5 \%$, but those for bins of 0 and of 7 and 8 are respectively less than 250 where the occurrence frequency may contain larger uncertainties of more than $10 \%$. The occurrence frequency of the ion upflow increases rather monotonically with the increasing $K_{P}$ values: about 0.15 at $K_{P}=1,0.2$ at $K_{P}=2,0.27$ at $K_{P}=3$ and 0.35 at $K_{P}=5$. The occurrence frequency of the downflow also increases with the increasing $K_{P}$ values unless the $K_{P}$ value is more than 3: about 0.1 at $K_{P}=1,0.2$ at $K_{P}=2$ and 0.23 at $K_{P}=3$. The difference between the upflow and 


\section{Definition of the ion upflow and downflow}

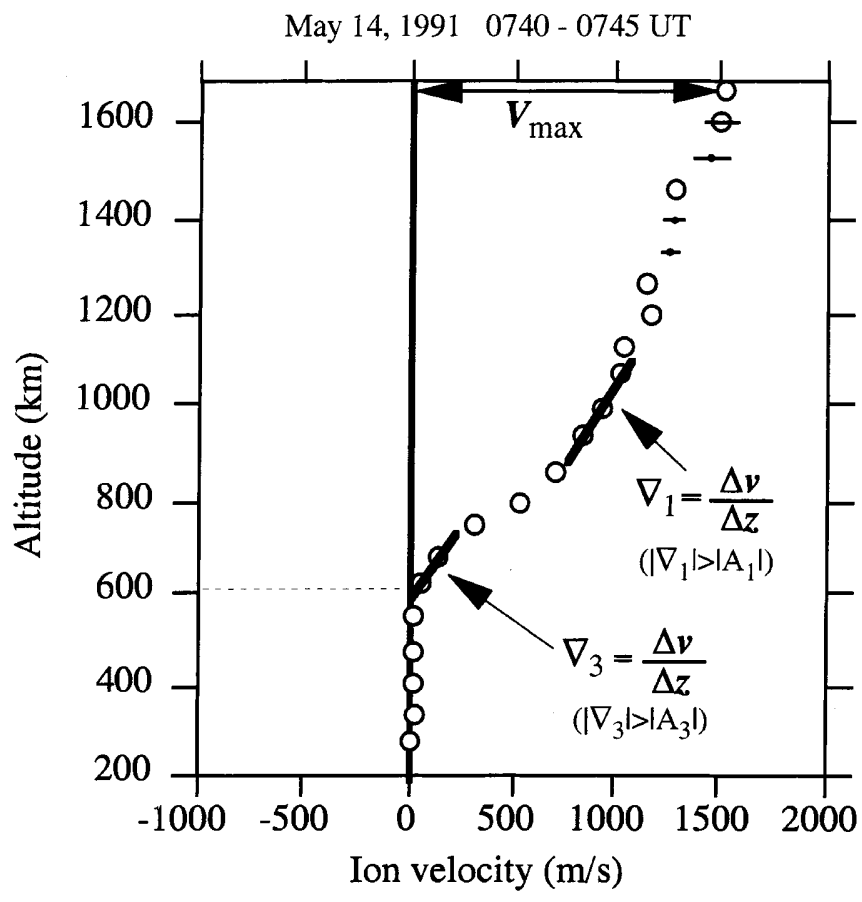

Fig. 3. The quantitative definition used in this study for selecting the ion upflow and downflow events from the CP 7 database. See text for the details

downflow at each $K_{P}$ level is smaller than 0.5 , implying that there is no significant net flow in terms of the occurrence frequency. When the $K_{P}$ values become larger than 3, the occurrence frequency of the downflow appears not to increase but to remain at a particular value. The $K_{P}$ dependence mentioned here again suggests that the net flow in terms of the occurrence frequency be small at the lower $K_{P}$ range but become significant at the higher $K_{P}$ range.

Figure 7 shows the $K_{P}$ dependence of the ion upflow and downflow in the four MLT regions, as those in Fig. 5; dawn, midday, dusk and midnight regions. The abscissa is again the $K_{P}$ levels and the ordinate is the occurrence frequency and the number of samples for each $K_{P}$ bin. Due to too small numbers of samples, we will see the occurrence frequency at $K_{P}=0 \sim 5$.

In the midnight region $(21 \leq \mathrm{MLT}<3)$, with the increasing $K_{P}$ values, the occurrence frequencies of both upflow and downflow increase at lower $K_{P}$ values

Table 2. The threshold criteria of the definition of ion upflow and downflow

\begin{tabular}{lllll}
\hline $\begin{array}{l}\text { Threshold } \\
\text { criteria }\end{array}$ & $\begin{array}{l}\text { Velocity } \\
\text { grad. Al } \\
(\mathrm{m} / \mathrm{s} / \mathrm{km})\end{array}$ & $\begin{array}{l}\text { Consecutive } \\
\text { number } N\end{array}$ & $\begin{array}{l}\text { Maximum } \\
\text { velocity A2 } \\
(\mathrm{m} / \mathrm{s})\end{array}$ & $\begin{array}{l}\text { Velocity } \\
\text { grad. A3 } \\
(\mathrm{m} / \mathrm{s} / \mathrm{km})\end{array}$ \\
\hline \pm 1 & \pm 0.2 & 3 & \pm 150 & \pm 0.3 \\
\pm 2 & \pm 0.3 & 4 & \pm 200 & \pm 0.4 \\
\pm 3 & \pm 0.4 & 5 & \pm 300 & \pm 0.5 \\
\hline
\end{tabular}

+ for ion upflow; - for ion downflow
(1 and 2) but appear to stop increasing at higher $K_{P}$ values (more than 2). The difference between the two occurrence frequencies is markedly small throughout all the $K_{P}$ values less than 6 , which is consistent with the occurrence frequencies at $21 \sim 03$ MLT in Fig. 4.

In the dawn $(3 \leq$ MLT $<9)$ and dusk $(15 \leq$ MLT $<$ 21 ), the occurrence frequencies of both the ion upflow and downflow increase monotonically with the increasing $K_{P}$ values. The occurrence frequency of the upflow is significantly greater than that of the downflow for all $K_{P}$ values.

In the midday $(9 \leq$ MLT $<15)$, with the increasing $K_{P}$, the occurrence frequencies of both the upflow and downflow increases at lower $K_{P}$ values $(1 \sim 3)$ without a significant difference between them. At higher $K_{P}$ values (more than 3), with the increasing $K_{P}$, the occurrence frequency of the upflow appears to increase slightly or remains at a particular value, while that of the downflow decreases.

\section{Discussion and conclusions}

The ion upflow has been considered to be a phenomenon that ionospheric ions flow out along the magnetic field line of forces. The CP 7 mode experiment, data from which we have used in this study, provides physical parameters, however, not in the magnetic field-aligned direction but in the vertical direction from 285 to $1654 \mathrm{~km}$ high. This offset of the beam direction from the field-aligned direction by $12.5^{\circ}$ obviously implies that a measured vertical ion motion is a combination of ion motions parallel to and perpendicular to the local magnetic field, as shown in Fig. 8. Only the geomagnetic northward component of the ion motion perpendicular to the magnetic field produces the vertical component of the ion motion while the eastward component does not.

Let us estimate the contamination of the perpendicular plasma motion in the north-south directions to the vertical motion. The vertical velocity $\mathrm{V}$ is a sum of the projections from the velocities perpendicular and parallel to the magnetic field to the vertical line.

$\mathrm{V}= \pm \mathrm{V}_{\|} \cos 12.5^{\circ} \pm \mathrm{V}_{\perp} \sin 12.5^{\circ}= \pm 0.98 \mathrm{~V}_{\|} \pm 0.22 \mathrm{~V}_{\perp}$

The contribution of the perpendicular plasma velocity to the vertical component is $22 \%$ of its velocity, that is, $\mathrm{V}=220 \mathrm{~m} / \mathrm{s}$ for $\mathrm{V}_{\perp}=1000 \mathrm{~m} / \mathrm{s}$ (equivalently about $50 \mathrm{mV} / \mathrm{m}$ electric field at $285 \mathrm{~km}$ ).

We will next estimate the change of the plasma velocity with altitudes. We assume the electric equipotentiality along a magnetic field line, a uniform plasma motion (equivalently a uniform electric field) in the region we consider, and a dipole magnetic field. Since the magnitude of the magnetic field is proportional to $\left(r / r_{0}\right)^{-3}$, where $r_{0}$ and $r$ are in each case the distance from the Earth's centre to $285 \mathrm{~km}$ altitude and to an altitude where the distance between two specific magnetic field lines aligned in the north-south direction is proportional to $\left(r / r_{0}\right)^{2}$. Hence, the southward and eastward components of the ion velocity perpendicular to the magnetic field, which is supposed to be $\mathbf{E} \times \mathbf{B}$ drift velocity, are 


\section{Case : +1 (Upflow)}

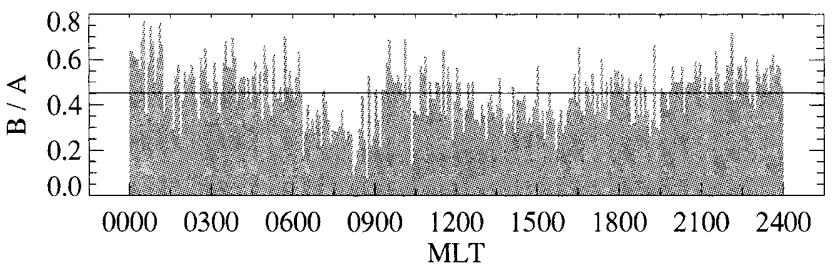

Case : +2 (Upflow)

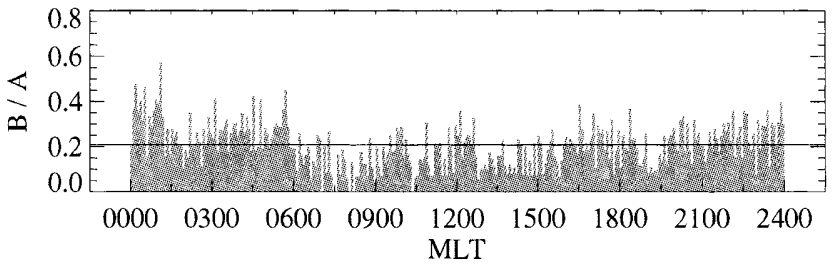

Case : +3 (Upflow)

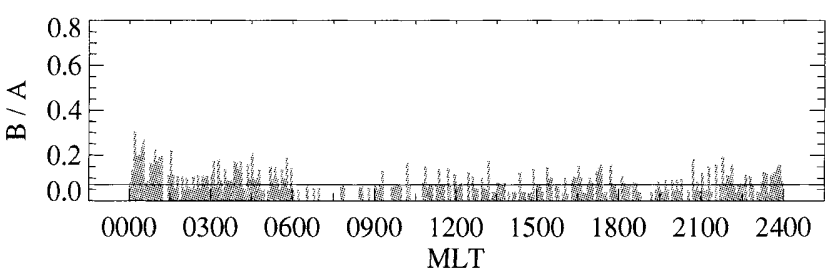

Case : -1 (Downflow)

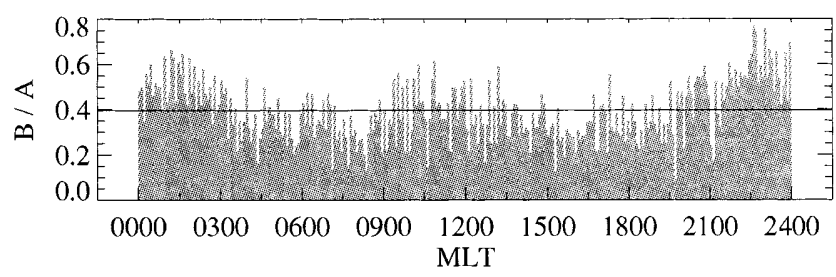

Case : -2 (Downflow)

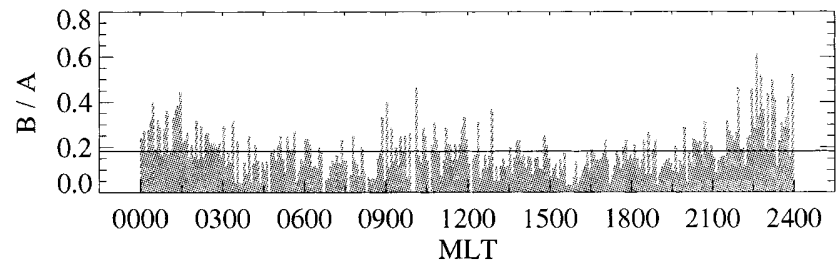

Case : -3 (Downflow)

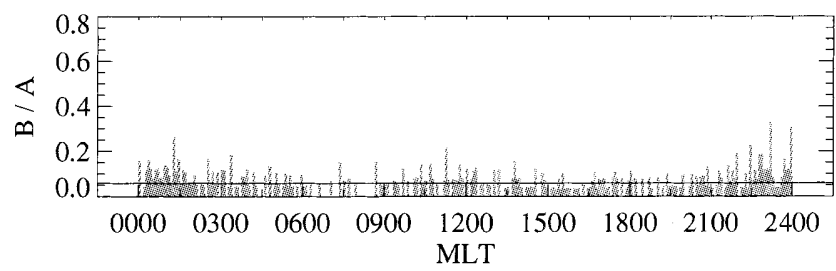

Fig. 4. The magnetic local time (MLT) distribution of the occurrence frequency of the ion upflow (left) and the downflow (right) for the threshold criterion 1 (case 1) through the threshold criterion 3 (case 3). For both ion upflow and downflow, data only under $K_{P}<4$ are selected

\section{$\mathrm{Kp}<4$}
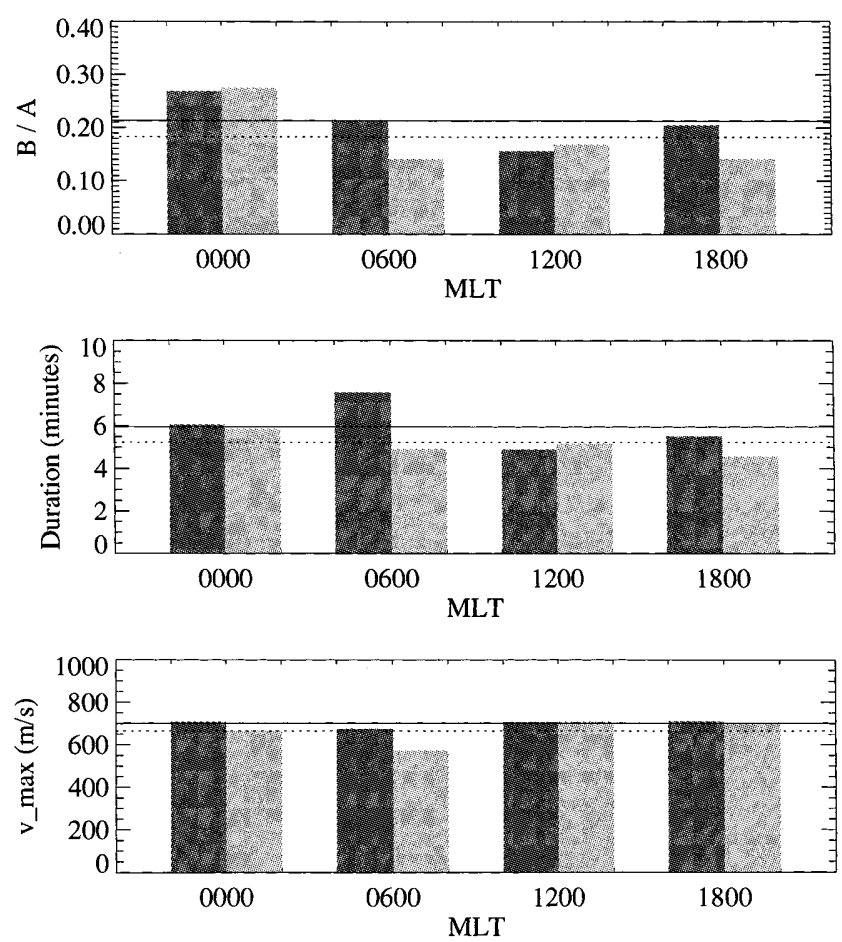

$\mathrm{Kp} \geq 4$ : Upflow 2......... : Downflow
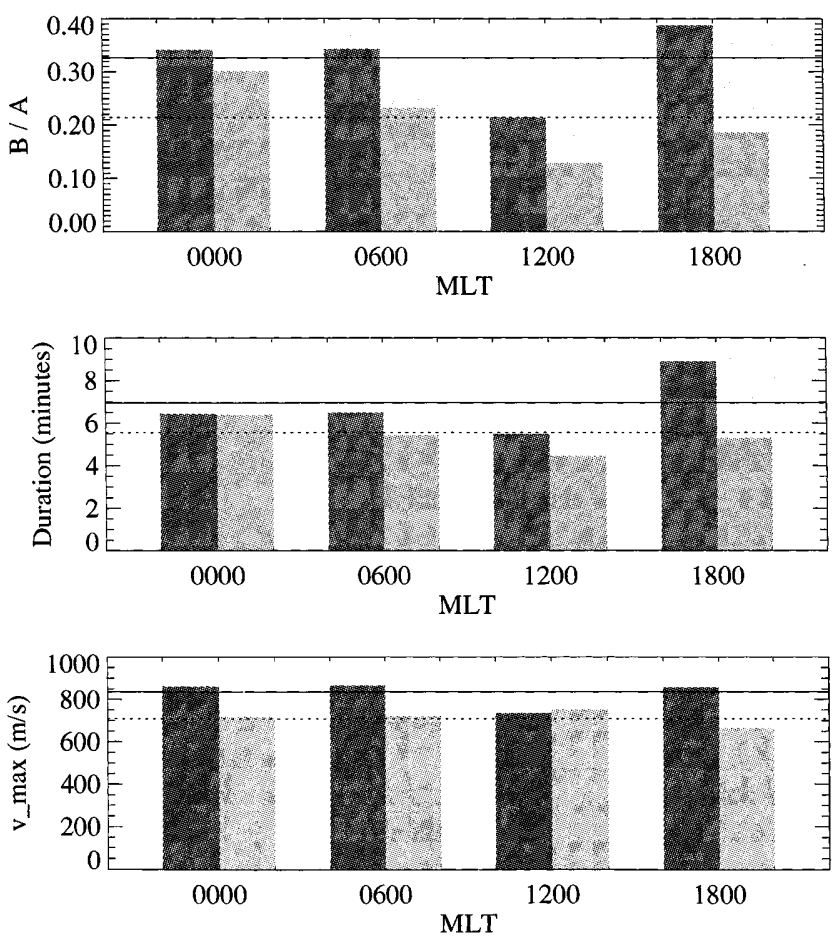

Fig. 5. The distributions of the upflow and downflow for four magnetic local time regions: $21 \leq$ MLT $<3,3 \leq$ MLT $<9,9 \leq$ MLT $<15$, and $15 \leq$ MLT $<21$, under two geomagnetic disturbance levels: $K_{P}<4$ for quite conditions and $K_{P} \geq 4$ for disturbed conditions 


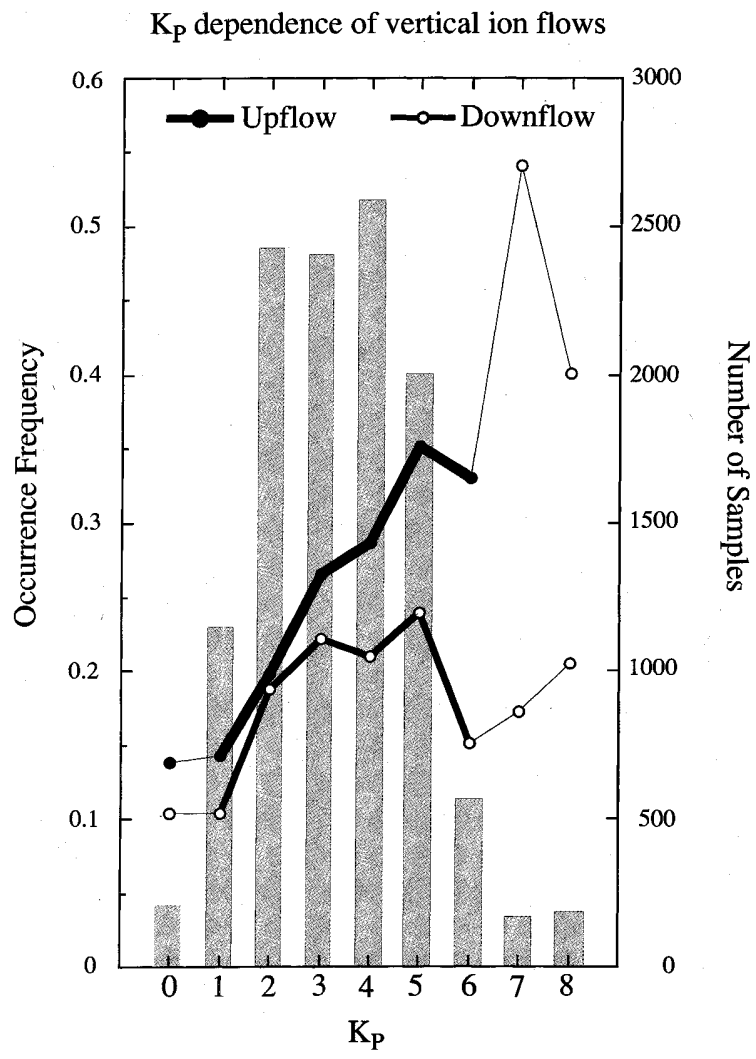

Fig. 6. The $K_{P}$ dependence of the ion upflow and downflow for all MLTs
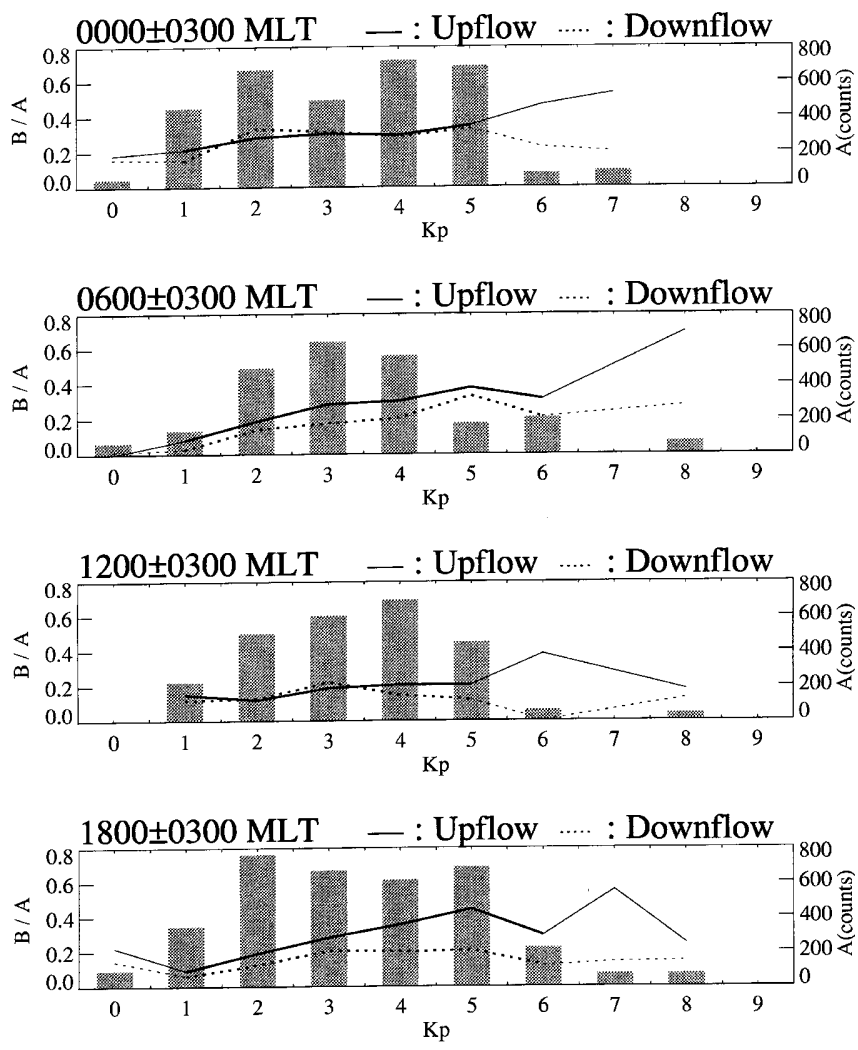

Fig. 7. The $K_{P}$ dependence of the ion upflow and downflow in the four MLT regions as in Fig. 5; dawn, midday, dusk and midnight regions

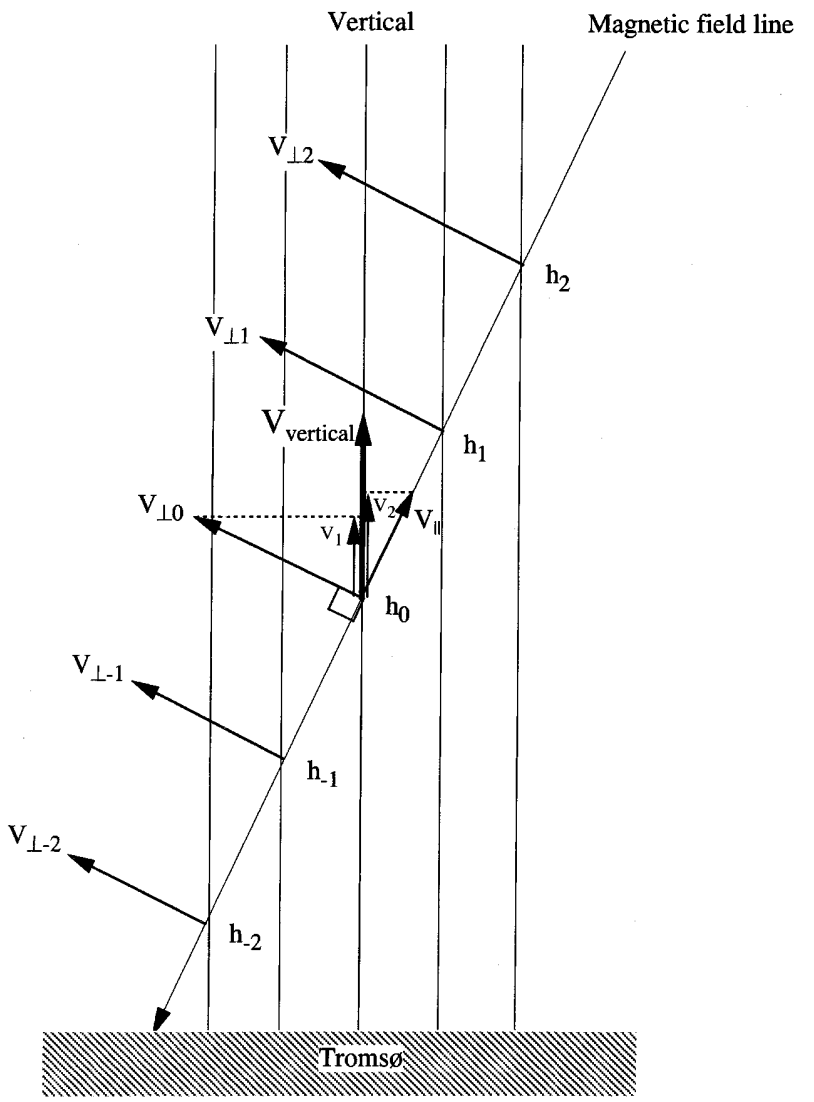

Fig. 8. Schematic diagram to show how the ion velocity components perpendicular to and parallel to the magnetic field line contribute to the vertical componen

proportional to $\left(r / r_{0}\right)^{2}$ and $\left(r / r_{0}\right)$, respectively. The northward and eastward velocities $\mathrm{V}_{\perp}$ perpendicular to the magnetic field at $1654 \mathrm{~km}$ are about 1.45 and 1.21 times larger than those at $285 \mathrm{~km}$, respectively.

Although the plasma velocity perpendicular to the magnetic field thus produces a certain amount of vertical velocity, the ion upflow and downflow events, e.g. shown in Fig. 1a, b, may not so much suffer such a contamination from the perpendicular component. There are two reasons for this. First, this vertical velocity may rarely exceed $200 \mathrm{~m} / \mathrm{s}$, since the perpendicular plasma velocity seldom becomes larger than the corresponding velocity $1000 \mathrm{~m} / \mathrm{s}$ (see e.g., Fig. 3a of Fujii et al., 1999). Hence the threshold criterion 2 for the maximum velocity $200 \mathrm{~m} / \mathrm{s}$ is reasonable. Second, as is obvious from the discussion, the contamination must be a relatively constant value along the vertical line, only slowly varying in magnitude. The height distribution of the ion upflow/downflow shown in Fig. 1a, b does not match this feature.

The ion upflow is characterised not only by the enhancement of the field-aligned ion velocity but also by the increases of the ion and/or electron temperatures (Wahlund et al., 1992). It is thus considered to be driven either by frictional heating or by ion heating through plasma instabilities that are excited by free energy from particle precipitation. Hence, the ion upflow is mainly located in the regions where an intense electric field and/ 
or precipitation is observed. Those regions are the polar cusp, the polar cap boundary, and the auroral zone. An ion outflow study with DE 1 satellite observations (Kondo et al., 1990) has indeed shown the enhancements of the ion outflow in these regions, in particular, around the polar cusp region.

Tromsø is located at $66^{\circ}$ invariant latitude (INV), and is thus most frequently in the sub-auroral zone in the midday time, in the auroral zone in the dawn and dusk, and in the auroral zone and sometimes in the polar cap through the polar cap boundary in the midnight region (Feldstein and Strakov, 1967). A reason why we see a smaller occurrence frequency of the ion upflow in the midday region than in other regions may be that the $66^{\circ}$ INV ionosphere overhead Tromsø at midday is relatively distant from the region where ion heating effectively takes place.

The driving force for the downflow ions appears to be the Earth's gravity by which the ions fall down after they are lifted up by the mechanisms mentioned. Unless upflowing ions have enough energy of motion to escape the Earth's gravity, they will come back to the ionosphere. Naturally this motion energy can become larger with increasing geomagnetic disturbances, since both particle precipitation and the electric field are enhanced accordingly. This is why the occurrence frequency of the ion upflow is rather monotonically increased with the increased of the $K_{P}$ index in all MLT regions.

The occurrence frequency of the ion upflow is nearly the same as that of the downflow for lower $K_{P}$ values, since enough energy is not given to ions to escape from the Earth's gravity. On the other hand, the occurrence frequency of the upflow becomes greater than that of the downflow with increasing $K_{P}$ index, since the ions tend to gain enough energy to escape from the Earth's gravity.

The difference of the occurrence frequencies between the ion upflow and downflow has also an MLT dependence. The difference is small in the midnight region, suggesting little net ion flow there, but larger differences between the two occurrence frequencies both in the dawn and dusk regions. Although we do not fully understand what causes this MLT dependence, one possible explanation is as follows. Statistically, the electric field strength, the electromagnetic energy input from the magnetosphere to the ionosphere and the Joule heating rate become largest in the dawn and dusk regions (Fujii et al., 1999), rather than in the midnight region. This MLT dependence may suggest that ions in the dawn and dusk regions more frequently obtain greater energy than those in the midnight region. On the other hand, in the midnight region we expect intense particle precipitation in terms of energy and flux particularly associated with substorms and storms. These precipitating plasmas with rather high energies ionise most efficiently neutral atmosphere in the lower $\mathrm{E}$ region but probably not so efficiently at higher altitudes where ions are heated up.

We have not discussed the fluxes of the ion upflow and downflow, which are highly dependent on the threshold criteria. These will be covered in future works together with the evaluation of these fluxes, their seasonal variations, spatial confinement and movement of the upflow/downflow.

\section{Summary}

We have determined the MLT distribution and $K_{P}$ dependence of ion upflow and downflow events based on a data analysis using the EISCAT VHF radar CP-7 data obtained at Tromsø.

1. Both ion upflow and downflow events can be observed at any local time (MLT), irrespective of dayside and nightside, and under any magnetic disturbance level, irrespective of quiet and disturbed levels.

2. These upflow and downflow events are more frequently observed in the nightside than in the dayside regions.

3. The upflow events are more frequently observed than the downflow events at any local time except midnight and at any $K_{P}$ level and the difference of the occurrence frequencies between the upflow and downflow events is smaller around midnight.

4. The occurrence frequencies of both the ion upflow and downflow events appear to increase with increasing $K_{P}$ level, while the occurrence frequency of the downflow appears to stop increasing at some $K_{P}$ level.

Acknowledgements We are indebted to the director and staff of EISCAT for operating the facility and supplying the data. EISCAT is an international association supported by Finland (SA), France (CNRS), the Federal Republic of Germany (MPG), Japan (NIPR), Norway (NFR), Sweden (NFR) and the United Kingdom (PPARC). This study was supported in part by a Grant-in-aid for International Scientific Research (09044074) and by Grants-inaid for Scientific Research A (08304030) and B (08454135) by the Ministry of Education, Science, Sports and Culture, Japan.

The Editor in chief thanks J. E. Wahlund and A. Yau for their help in evaluating this paper.

\section{References}

Abe, T., B. A. Whalen, A. W. Yau, R. E. Horita, S. Watanabe, and E. Sagawa, EXOS D (Akebono) suprathermal mass spectrometer observations of the polar wind, J. Geophys. Res., 98, 11 191, 1993a.

Abe, T., B. A. Whalen, A. W. Yau, S. Watanabe, E. Sagawa, and K. I. Oyama, Altitude profile of the polar wind velocity and its relationship to ionospheric conditions, Geophys. Res. Lett., 20, 2825,1993 b.

André, M., and A. W. Yau, Theories and observations of ion energization and outflow in the high latitude magnetosphere, Space Sci. Rev., 80(1/2), 27, 1997.

Axford, W. I., The polar wind and the terrestrial helium budget, J. Geophys. Res., 73, 6855, 1968.

Banks, P. M., and T. E. Holzer, The polar wind, J. Geophys. Res., 73, 6846, 1968.

Banks, P. M., and T. E. Holzer, Features of plasma transport in the upper atmosphere, J. Geophys. Res., 74, 6304, 1969a.

Banks, P. M., and T. E. Holzer, High-latitude plasma transport: the polar wind, J. Geophys. Res., 74, 6317, $1969 \mathrm{~b}$. 
Bauer, S. J., The structure of the topside ionosphere, in Electron Density Profiles in Ionosphere and Exosphere, Ed. J. Frihagen, p. 387, North-Holland, Amsterdam, 1966.

Blelly, P. L., A. R. Barakat, J. Fontanari, D. Alcayde, M. Blanc, J. $\mathrm{Wu}$, and C. Lathullere, Observations of the structure and vertical transport of the polar upper ionosphere with the EISCAT VHF radar. 1. Is EISCAT able to determine and polar wind characteristic? A simulation study, Ann. Geophysicae, 10, 367, 1992

Blelly, P. L., J. Fontanari, D. Alcayde, J. Wu, M. Blanc, and T. L. Hansen, Observations of the structure and vertical transport of the polar upper ionosphere with the EISCAT VHF radar 3. Topside neutral composition and quiet-time temperature, Ann. Geophysicae, 10, 394, 1992.

Chandler, M. O., J. H. Waite, Jr., and T. E. Moore, Observations of polar ion outflows, J. Geophys. Res., 96, 1421, 1991.

Chappell, C. R., The terrestrial plasma source: a new perspective in solar-terrestrial processes from Dynamics Explorer, Rev. Geophys., 26, 229, 1988.

Demars, H. G., and R. W. Schunk, Comparison of solutions of bi Maxwellian and Maxwellian transport equations for subsonic flows, J. Geophys. Res., 92, 5969, 1987.

Dessler, A. J., and F. C. Michel, Plasma in the geomagnetic tail, J. Geophys. Res., 71, 1421, 1966.

EISCAT Scientific Association, The first decade of operations: catalogue of operations 1981-1990, EISCAT Scientific Association, Sweden, 1991

Feldstein, Y. I., and G. V. Starkov, Dynamics of auroral belt and polar geomagnetic disturbances, Planet. Space Sci., 15, 209, 1967.

Forme, F. R. E., and D. Fontaine, Enhanced ion acoustic fluctuations and ion outflows, Ann. Geophysicae, 17, 182, 1999.

Fujii, R., S. Nozawa, S. C. Buchert, N. Matuura, and A. Brekke, The motion of ions in the auroral ionosphere, J. Geophys. Res., 103, 20 685-20 695, 1998.

Fujii, R., S. Nozawa, S. C. Buchert, N. Matuura, and A. Brekke, Statistical characteristics of electromagnetic energy transfer between the magnetosphere, the ionosphere, and the thermosphere, J. Geophys. Res., 104, 2357, 1999.

Ganguli, S. B., H. G. Mitchell, Jr., and P. J. Palmadesso, Behavior of ionized plasma in the high latitude topside ionosphere: the polar wind, Planet. Space Sci., 35, 703, 1987.

Gombosi, T. L., and A. F. Nagy, Time-dependent modeling of the field-aligned current-generated ion transients in the polar wind, J. Geophys. Res., 94, 359, 1989.

Hirahara, M., T. Mukai, T. Terasawa, S. Machida, Y. Saito, T. Yamamoto, and S. Kokubun, Cold dense ion flows with multiple components observed in the distant tail lobe by Geotail, J. Geophys. Res., 101, 7769, 1996.

Hoffman, J. H., Studies and composition of the ionosphere with a magnetic deflection mass spectrometer, Int. J. Mass Spectrum. Ion Phys., 4, 325, 1970.

Hoffman, J. H., W. H. Dodson, C. R. Lippincott, and H. D. Hammack, Initial ion composition results from the ISIS 2 satellite, J. Geophys. Res., 79, 4246, 1974.

Horwitz, J. L., and T. E. Moore, Four contemporary issues concerning ionospheric plasma flow to the magnetosphere, Space Sci. Rev., 80(1/2), 49, 1997.

Kondo, T., B. A. Whalen, A. W. Yau, and W. K. Peterson, Statistical analysis of upflowing ion beam and conic distributions at DE 1 altitudes, J. Geophys. Res., 95, 12 091, 1990.

Lemaire, J., and M. Scherer, Model of the polar ion-exosphere, Planet Space Sci., 18, 103, 1970.

Lemaire, J., and M. Scherer, Kinetic models of the solar and polar winds, Rev. Geophys., 11, 427, 1973.

Loranc, M., and J.-P. St.-Maurice, A time-dependent gyro-kinetic model of thermal ion upflows in the high-latitude $\mathrm{F}$ region, J. Geophys. Res., 99, 17 429, 1994.
Marubashi, K., Escape of the polar ionospheric plasma into the magnetospheric tail, Rep. Ionos. Space Res. Jpn., 24, 322, 1970.

Moore, T. E., Superthermal ionospheric outflows, Rev. Geophys. Space Phys., 22, 264, 1984.

Mukai, T., M. Hirabara, S. Machida, Y. Saito, T. Terasawa, and A. Nishida, Geotail observations of cold ion streams in the medium distance magnetotail lobe in the course of a substorm, Geophys. Res. Lett., 21, 1023, 1994.

Nagai, T., J. H. Waite, J. L. Green, C. R. Chappell, R. C. Olsen, and R. H. Comfort, First measurements of supersonic polar wind in the polar magnetosphere, Geophys. Res. Lett., 11, 669, 1984.

Nishida, A., Formation of a plasmapause, or magnetospheric plasma knee by combined action of magnetospheric convection and plasma escape from the tail, J. Geophys. Res., 71, 5669, 1966.

Raitt, W. J., R. W. Schunk, and P. M. Banks, The influence of convection electric fields on thermal proton outflow from the ionosphere, Planet. Space Sci., 25, 291, 1977.

Raitt, W. J., R. W. Schunk, and P. M. Banks, A comparison of the temperature and density structure in the high and low speed thermal proton flows, Planet. Space Sci., 23, 1103, 1975.

Rietveld, M. T., P. N. Collis, and J.-P. St.-Maurice, Naturally enhanced ion acoustic waves in the auroral ionosphere observed with the EISCAT 933-MHz radar, J. Geophys. Res., 96, 19 291, 1991.

Schunk, R. W., and D. S. Watkins, Electron temperature anisotropy in the polar wind, J. Geophys. Res., 86, 91, 1981.

Schunk, R. W., and D. S. Watkins, Proton temperature anisotropy in the polar wind, J. Geophys. Res., 87, 171, 1982.

Schunk, R. W., and J. J. Sojka, A three-dimensional timedependent model of the polar wind, J. Geophys. Res., 94, 8973, 1989.

Schunk, R. W., W. J. Raitt, and A. F. Nagy, Effect of diffusion thermal processes on the high-latitude topside ionosphere, Planet. Space Sci., 26, 189, 1978.

Seki, K., M. Hirahara, T. Terasawa, I, Shinohara, T. Mukai, Y. Saito, S. Machida, T. Yamamoto, and S. Kokubun, Coexistence of Earth-orgin $\mathrm{O}^{+}$and solar wind-orgin $\mathrm{H}^{+} / \mathrm{H}^{++}$in the distant magnetotail, Geophys. Res. Lett., 23, 985, 1996.

Seki, K., M. Hirahara, T. Terasawa, T. Mukai, Y. Saito, S. Machida, T. Yamamoto, and S. Kokubun, Statistical properties and possible supply mechanisms of tailward cold $\mathrm{O}^{+}$beams in the lobe/mantle region, J. Geophys. Res., 103, 4477, 1998.

Shelley, E. G., W. K. Peterson, A. G. Ghielmetti, and J. Geiss, The polar ionosphere as a source of energetic magnetospheric plasma, Geophys. Res. Lett., 9, 941, 1982.

Taylor, H. A., Jr., and W. J. Walsh, The light ion trough, the main trough, and the plasmapause, J. Geophys. Res., 77, 6716, 1972.

Wahlund, J.-E., H. J. Opgenoorth, I. Häggström, K. J. Winser, and G. O. L. Jones, EISCAT observation of topside ionosphere ion outflows during auroral activity: revisited, J. Geophys. Res., 97, 3019, 1992.

Wahlund, J.-E., H. J. Opgenoorth, F. R. E. Forme, M. A. L. Persson, I. Häggström, and J. Lilensten, Electron energization in the topside auroral ionosphere: on the importance of ionacoustic turbulence, J. Atmos. Terr. Phys., 55, 623, 1993.

Watanabe, S., B. A. Whalen, and A. W. Yau, Thermal ion observation of depletion and refilling in the plasmaspheric trough, J. Geophys. Res., 97, 1081, 1992.

Wilson, G. R., Kinetic modelling of $\mathrm{O}^{+}$upflows resulting from ExB convection heating in the high-latitude $\mathrm{F}$ region ionosphere, J. Geophys. Res., 99, 17 453, 1994.

Wu, J., M. Blanc, D. Alcayde, A. R. Barakat, J. Fontanari, P. L. Blelly, and W. Kofman, Observation of the structure and vertical transport of the polar upper ionosphere with the EISCAT VHF radar. 2. First investigations of the topside and vertical ion flows, Ann. Geophysicae, 10, 375, 1992. 
Yau, A. W., and M. André, Sources of ion outflow in the high latitude ionosphere, Space Sci. Rev., 80(1/2), 1, 1997.

Yau, A. W., B. A. Whalen, and E. Sagawa, Minor ion composition in the polar ionosphere, Geophys. Res. Lett., 18, 345, 1991.

Yau, A. W., B. A. Whalen, and C. Goodenough, EXOS D (Akebono) observations of molecular and upflowing ions in the high altitude auroral ionosphere, J. Geophys. Res., 98, $11205,1993$.

Yau, A. W., B. A. Whalen, T. Abe, T. Mukai, K. I. Oyama, and T. Chang, Akebono observations of electron temperature anisotropy in the polar wind, J. Geophys. Res., 100, 17 451, 1995. 